\title{
Analysis of Some Compliance Calibration Data for Chevron-Notch Bar and Rod Specimens
}

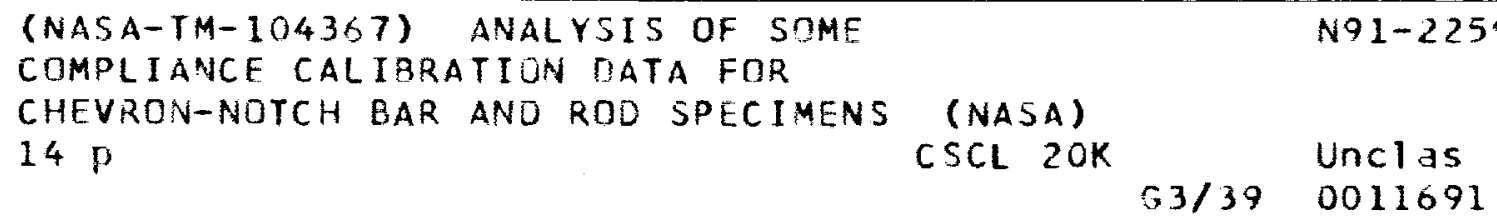

Thomas W. Orange, Raymond T. Bubsey, William S. Pierce, and John L. Shannon, Jr.

Lewis Research Center

Cleveland, Ohio

Prepared for the

Symposium on Chevron-Notch Fracture Test Experience

sponsored by the American Society for Testing and Materials

Indianapolis, Indiana, May 6, 1991 


\title{
ANALYSIS OF SOME COMPLIANCE CALIBRATION DATA FOR CHEVRON-NOTCH BAR AND ROD SPECIMENS
}

\author{
Thomas W. Orange, Raymond T. Bubsey, 'William S. Pierce," and John L. Shannon, Jr. \\ National Aeronautics and Space Administration \\ Lewis Research Center \\ Cleveland, Ohio $\mathbf{4 4 1 3 5}$
}

\section{SUMMARY}

This paper presents a set of equations describing certain fracture mechanics parameters for chevron-notch bar and rod specimens. They are developed by fitting earlier compliance calibration data. The difficulty in determining the minimum stress intensity coefficient and the critical crack length is discussed.

\section{INTRODUCTION}

This paper presents a set of equations describing certain fracture mechanics parameters for chevron-notch bar and rod specimens. They are developed by fitting previously reported experimental compliance calibration data. Their use will facilitate the testing and analysis of both brittle metals and the tougher ceramics. The equations present the various parameters in forms suitable for determining fracture toughness from maximum load, for determining the crack-extension resistance curve (R-curve), and for setting instrument sensitivities. The data encompass the entire range of the specimen geometries most commonly used.

We first discuss briefly the background of the chevron-notch specimens and the experimental data to be used. Then we present a more extensive discussion on some particular characteristics of the chevron-notch specimens and their practical application. The fitted equations are presented and their fitting accuracies are discussed. Finally, problems in determining the minimum stress intensity coefficient and the critical crack length are discussed.

\section{SYMBOLS}

$\begin{array}{ll}a & \text { Crack length (measured from load line) } \\ a_{0} & \text { Distance from load line to tip of chevron } \\ a_{m} & \text { Crack length at which } Y^{*} \text { is minimum } \\ B^{\prime} & \text { Specimen thickness } \\ C & \text { Specimen compliance, } C=E B V / P \\ C^{\prime} & \text { Compliance derivative, } d C / d \alpha \\ D & \text { Diameter (rod), } D=B\end{array}$

'Retired. 


$\begin{array}{ll}E & \text { Elastic (Young's) modulus } \\ K_{1} & \text { Opening-mode stress intensity factor } \\ K_{\mathrm{w}} & \text { Plane-strain fracture toughness for chevron-notch specimens } \\ P & \text { Applied load } \\ V & \text { Crack mouth opening displacement } \\ W & \text { Width } \\ Y & \text { Dimensionless stress intensity factor for a crack in a chevron notch, } \\ & K B W^{1 / 2} / P \\ Y_{m} & \text { Minimum value of } Y \text { as a function of } \alpha \\ \alpha & a / W \\ \alpha_{0} & a_{0} W \\ \alpha_{m} & a_{m} W\end{array}$

\section{BACKGROUND}

The chevron-notch specimens are fairly recent additions to the field of fracture mechanics. Consequently they do not have the same historical background of extensive stress intensity and displacement analysis as do the more common specimen types. But, like the earliest specimen types, we can develop useful expressions using experimental compliance data.

Compliance data for the chevron-notch bar [1] and rod [2] specimens were previously reported. In each paper, one fitted equation was presented relating the minimum stress intensity factor to the initial crack length and to the specimen dimensions. A later paper [3] reported additional data for specimens having smaller initial crack lengths and also revised the previous equations to cover the wider range of crack lengths. But those equations alone are not sufficient for all analyses and tests involving high-toughness ceramics. To make them more complete and useful, a new set of generalized equations are presented in this paper. These equations are developed by fitting curves to the existing data. They are usable over a wide range of specimen dimensions.

\section{CHARACTERISTICS OF CHEVRON-NOTCH SPECIMENS}

For most common fracture test specimens, the dimensionless stress intensity factor $(M$ increases continually with increasing relative crack length $(a / M)$. But due to the wedge shape of the un-notched material in the chevron-notch specimen, the corresponding factor $\left(Y^{*}\right)$ reaches a minimum, denoted $Y_{m}^{*}$, as the crack length reaches a value denoted $a_{m}$. The values of $Y_{m}$ and $\alpha_{m}$ are functions of specimen dimensions and notch geometry only and are independent of material properties.

If the material being tested has a crack growth resistance curve which increases rapidly to a relatively constant plateau (known as a "flat" R-curve), instability will occur at $a=a_{m}$ and $P=P_{\max }$. Then the fracture toughness $\left(K_{w}\right)$ can be calculated from 


$$
K_{I v}=Y_{m}^{*} \frac{P_{\max }}{B W^{1 / 2}}
$$

and no other test measurements are necessary.

For some materials (even some ceramics), however, the R-curve does not reach a plateau but continues to increase with increasing crack extension (a "rising" R-curve). For such materials eqn. (1) does not apply and it may be desirable to determine the complete R-curve. In this case ASTM Test Method E 561 [4] may be used for guidance. If crack mouth opening displacement (CMOD) is measured during the test (as in E561) and appropriate compliance relations are available, one can calculate the instantaneous crack length. From crack length and load, one can calculate the crack extension resistance as

$$
K_{I}=Y^{*} \frac{P}{B W^{1 / 2}}
$$

A plot of crack extension resistance against crack advance is the R-curve.

Experimental

\section{PROCEDURE}

The experimental procedure is described in detail in Refs $[1,2]$. The complete data are presented in Ref [5]. At least three replicate tests for each crack length were averaged to obtain the data reported here. For each specimen, 7 to 15 crack lengths (depending on the initial crack length) were tested.

Basic data reduction

Analysis of the data is based on the following equation [1]

$$
Y^{*}=\left[\frac{1}{2} \frac{\alpha_{1}-\alpha_{0}}{\alpha-\alpha_{0}} \frac{d}{d \alpha} \frac{E B V}{P}\right]^{1 / 2}
$$

and its derivative with respect to $\alpha$. In [1-3] the logarithms of the basic compliance data $(C=E B V / P)$ were fit with a fourth degree polynomial in $\alpha$. The fitted curve was differentiated and the values of $Y^{*}$ calculated from Eq 3.

In Ref [1] the reported values of $Y_{m}$ and $\alpha_{m}$ corresponded to the minimum of that fitted curve. In Ref [2], $Y_{m}$ and $\alpha_{m}$ were determined in the same way, but the data range was restricted to seven points symmetrical about the value of $\alpha_{m}$ found by the first fitting. Ref [3] used still another procedure. Seven points were selected by the previous criterion. Then a fourth degree polynomial was fit to the logarithms of the 
compliance derivatives. That second polynomial was used to calculate $Y_{m}$ and $\alpha_{m}$. In the process of verifying these calculations, some general concerns arose concerning procedures for determining $Y_{m}^{*}$ and $\alpha_{m}$. These will be discussed later.

Development of generalized equations

The following expressions are useful for computing the plane strain fracture toughness $K_{w}$ when the material has a relatively "flat" R-curve.

$$
\alpha_{m}=A_{0}+A_{1} \alpha_{0}+A_{2} \alpha_{0}^{2}+A_{3} \alpha_{0}^{3}
$$

and

$$
Y_{m}^{*}=B_{0}+B_{1} \alpha_{0}+B_{2} \alpha_{0}^{2}+B_{3} \alpha_{0}^{3}
$$

These were developed by first fitting third-degree polynomials in $\alpha_{0}$ for each specimen type (bar or rod) and each value of $W / B$. Then the coefficients of the intermediate polynomials were in turn fit to a second-degree polynomial in $W / B$ to produce the final forms of Eqns (4) and (5). Values of the coefficients for Eqns (4) and (5) are given in Tables 1 and 2, respectively.

An expression for determining the relative crack length $\alpha$ as a function of measured displacements is

$$
\alpha=C_{0}+C_{1} U+C_{2} U^{2}+C_{3} U^{3}+C_{4} U^{4}
$$

where $U$ is the Saxena and Hudak form [6]

$$
U=\frac{1}{\left(\frac{E B V}{P}\right)^{1 / 2}+1}
$$

The coefficients for Eqn (6) are given in Table 3. This equation lends itself to computer-controlled fracture toughness testing since the subcritical crack growth can be determined from automated load and displacement data acquisition.

When the relative crack length $\alpha$ is known, the stress intensity factor $\gamma^{*}$ and the dimensionless compliance EBV/P can be computed from the following expressions:

$$
Y^{*}=e^{D_{0}+D_{1} \alpha+D_{2} \alpha^{2}+D_{3} \alpha^{3}+D_{4} \alpha^{*}}
$$

and 


$$
\frac{E B V}{P}=e^{E_{0}+E_{1} \alpha+E_{2} \alpha^{2}+E_{3} \alpha^{3}+E_{4} \alpha^{4}}
$$

The coefficients for Eqns (7) and (8) are given in Tables 4 and 5, respectively.

\section{DISCUSSION}

\section{Generalized equations}

Eqn (4) fits the calculated values of $\alpha_{m}$ within $0.013 W$ for the bar specimens and within $0.006 \mathrm{~W}$ for the rod specimens. Eqn (5) fits the calculated values of $\gamma_{m}$ within $1.0 \%$ for the bar specimens and within $2.7 \%$ for the rod specimens.

Within the ranges of $\alpha$ and $\alpha_{0}$ specified in Tables 3 to 5, Eqn (6) fits the measured values of $\alpha$ within $0.003 W$ for the bar specimen and within $0.002 W$ for the rod specimen; Eqn (7) fits the calculated values of $Y^{*}$ within $2.9 \%$ for the bar specimen and within $2.1 \%$ for the rod specimen; and Eqn (8) fits the measured values of EBV/P within $1.4 \%$ for both the bar and the rod specimen.

Table 3 of Ref [7] gives values of $Y_{\mathrm{m}}$ and a critical slope ratio $r_{\mathrm{c}}$. That ratio is the ratio of the compliances corresponding to $\alpha_{m}$ and $\alpha_{0}$. For specimens with $W / B=2.0$, the values of $Y_{m}$ computed from Eq (5) for both the bar and rod specimens are within $0.6 \%$ of those in Ref [7]. The critical slope ratio computed from Eq (8) is within $1 \%$ for the bar specimen but is $7.8 \%$ low for the rod specimen.

Problems in determining $\gamma_{m}$ and $\alpha_{m}$

The method of data analysis used in Ref [3] was not given explicitly and could not be determined directly from archival records. In attempting to verify the numerical analysis (by duplication), several methods were tried. Each produced a significantly different value for $\alpha_{m}$ for the same data set, and this is a problem that should be discussed.

The problem is inherent in the chevron-notch specimen. It is due to the same characteristic that makes it desirable, namely the fact that $Y$ has a minimum. For example, assume that we have a function $f$ such that

$$
E B V / P=f(\alpha)
$$

where $f$ includes the data transform (if any) and a fitting function. Substituting this into the derivative of Eq (3) and eliminating non-zero terms we have

$$
0=\frac{1}{\alpha_{m}-\alpha_{0}} f^{\prime}\left(\alpha_{m}\right)-f^{\prime \prime}\left(\alpha_{m}\right)
$$

where $f^{\prime}$ and $f^{\prime \prime}$ are the first and second derivatives and $\alpha_{m}$ is the root of this equation. 
Unlike simpler specimens, we need to determine the second derivative as well. This presents a strong challenge to the analyst.

Fig 2, from Ref [1], shows the typical variation of $Y$ with $\alpha$ for different values of $\alpha_{0}$. Experimental compliance data would be expected to scatter about these lines. It is apparent from this figure that for a short initial crack (say, $\left.\alpha_{0}=0.2\right) Y_{\mathrm{m}}$ will be relatively insensitive to the method of curve fitting but $\alpha_{m}$ will be very sensitive. However, for a long initial crack (say, $\alpha_{0}=0.5$ ) the opposite will be true.

Thus if the primary objective of the test is to determine $K_{\mathrm{N}}$, the initial crack length should be short. This is the case in Ref [7]. However, a long initial crack length is preferable if the critical crack length is important for, say, fractographic purposes.

It should be pointed out that numerical analyses (i.e., finite element or boundary integral methods) are subject to the same problem, although to a lesser degree. Discrete pairs of $\left(r^{*}, \alpha_{0}\right)$ for several initial crack lengths must be fitted with a function to calculate a minimum. Three pairs are required, more would be preferred.

\section{CONCLUSIONS}

The equations presented here are in forms suitable for several purposes in fracture testing with chevron-notch specimens. They encompass the range of specimen geometries most commonly used and provide a good fit with the basic compliance data. The inherent difficulty in determining the critical crack length from compliance measurements is discussed.

\section{REFERENCES}

[1] Munz, D., Bubsey, R. T., and Srawley, J. E., "Compliance and Stress Intensity Coefficients for Short Bar Specimens with Chevron Notches," International Journal of Fracture, Vol. 16, No. 4, August 1980, pp. 359-374.

[2] Bubsey, R. T., Munz, D., Pierce, W. S., and Shannon, J. L., Jr, "Compliance Calibration of the Short Rod Chevron-Notch Specimen for Fracture Toughness Testing of Brittle Materials," International Journal of Fracture, Vol. 18, No. 2, February 1982, pp. 125-133.

[3] Shannon, J. L., Jr., Bubsey, R. T., Pierce, W. S., and Munz, D., "Extended Range Stress Intensity Factor Expressions for Chevron-Notched Short Bar and Short Rod Fracture Toughness Specimens," International Journal of Fracture, Vol. 19, No. 3, July 1982, pp. R55-R58. 
[4] Standard Practice for R-Curve Determination, ASTM E 561-86, Annual Book of ASTM Standards, Vol. 03.01, 1990.

[5] Bubsey, R. T., Orange, T. W., Pierce, W. S., and Shannon, J. L., Jr., "ClosedForm Expressions for Crack-Mouth Displacements and Stress Intensity Factors for Chevron-Notched Short Bar and Short Rod Specimens Based on Experimental Compliance Measurements," NASA TM 83796, 1991.

[6] Saxena, A., and Hudak, S. J., Jr., "Review and Extension of Compliance Information for Common Crack Growth Specimens," International Journal of Fracture, Vol. 14, No. 5, October 1978, pp. 453-468.

[7] Standard Test Method for Plane-Strain (Chevron-Notch) Fracture Toughness of Metallic Materials, ASTM E 1304-89, Annual Book of ASTM Standards, Vol. 03.01, 1990. 
Table 1--Coefficients for Eq 1

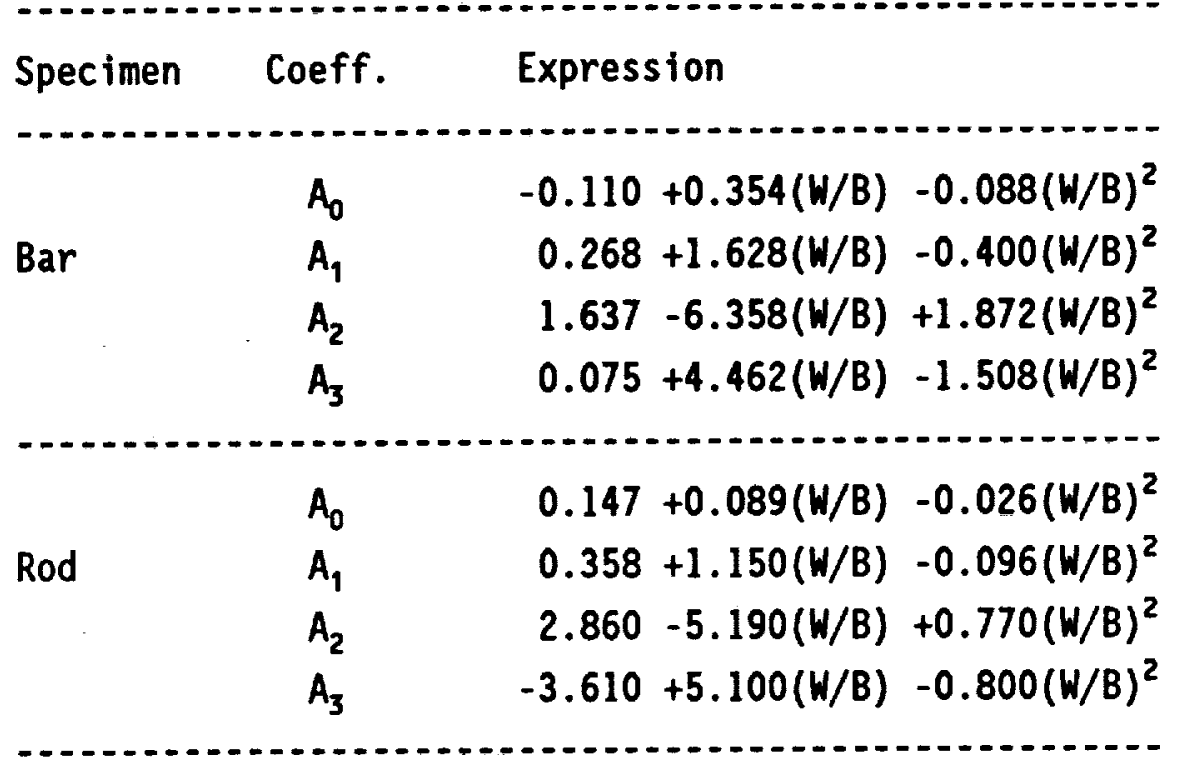

Range: $1.5 \leq(W / B) \leq 2.0,0 \leq \alpha_{0} \leq 0.5$

Table 2--Coefficients for Eq 5

Specimen Coeff. Expression

\begin{tabular}{|c|c|c|c|c|}
\hline & $\mathrm{B}_{0}$ & -17.03 & $+29.94(\mathrm{~W} / \mathrm{B})$ & $-5.0(W / B)^{2}$ \\
\hline \multirow[t]{3}{*}{ Bar } & $B_{1}$ & -116.00 & $+141.60(W / B)$ & $-29.6(W / B)^{2}$ \\
\hline & $B_{2}$ & 1131.00 & $-1304.00(W / B)$ & $+342.0(W / B)^{2}$ \\
\hline & $B_{3}$ & -1351.00 & $+1654.00(W / B)$ & $-443.2(W / B)^{2}$ \\
\hline & $B_{0}$ & 5.47 & $+6.29(W / B)$ & $+2.46(W / B)^{2}$ \\
\hline \multirow[t]{3}{*}{ Rod } & $B_{1}$ & -65.93 & $+72.62(W / B)$ & $-5.62(W / B)^{2}$ \\
\hline & $B_{2}$ & 622.00 & $-659.80(W / B)+$ & $146.10(W / B)^{2}$ \\
\hline & $\mathrm{B}_{3}$ & -541.40 & $+629.10(W / B)$ & $135.20(W / B)^{2}$ \\
\hline
\end{tabular}

Range: $1.5 \leq(W / B) \leq 2.0,0 \leq \alpha_{0} \leq 0.5$ 
Table 3--Coefficients for Eq 6

Specimen Coeff. Expression

\begin{tabular}{|c|c|c|c|c|c|}
\hline & $C_{0}$ & 3.09 & $-24.12 \alpha_{0}$ & & $+57.12 \alpha_{0}^{2}$ \\
\hline Bar & $c_{1}$ & -109.30 & $+1227.00 \alpha_{0}$ & -2 & $876.00 \alpha_{0}^{2}$ \\
\hline \multirow[t]{3}{*}{$W / B=1.5$} & $C_{2}$ & 1908.00 & $-22216.00 \alpha_{0}$ & +51 & $286.00 \alpha_{0}^{2}$ \\
\hline & $C_{3}$ & $-14900.00+$ & $+168580.00 \alpha_{0}$ & -381 & $240.00 \alpha_{0}^{2}$ \\
\hline & $\mathrm{C}_{4}$ & $41390.00-$ & $-451059.00 \alpha_{0}$ & +987 & $080.00 \alpha_{0}^{2}$ \\
\hline & $C_{0}$ & 2.08 & $-8.74 \alpha_{0}$ & & $+16.93 \alpha_{0}^{2}$ \\
\hline Bar & $c_{1}$ & -63.31 & $+540.00 \alpha_{0}$ & $-1 c$ & $019.00 \alpha_{0}^{2}$ \\
\hline \multirow[t]{3}{*}{$W / B=2.0$} & $c_{2}$ & 1086.00 & $-11296.00 \alpha_{0}$ & $+20 c$ & $043.00 \alpha_{0}^{2}$ \\
\hline & $c_{3}$ & -9327.00 & +98493.00 $\alpha_{0}-$ & $-158 \epsilon$ & $690.00 \alpha_{0}^{2}$ \\
\hline & $C_{4}$ & $28430.00-2$ & $284970.00 \alpha_{0}+$ & +3663 & $330.00 \alpha_{0}^{2}$ \\
\hline & $C_{0}$ & 0.672 & $+4.85 \alpha_{0}$ & & $-23.93 \alpha_{0}^{2}$ \\
\hline Rod & $c_{1}$ & 25.670 & $-361.90 \alpha_{0}$ & & $+1624.00 \alpha_{0}^{2}$ \\
\hline \multirow[t]{3}{*}{$W / B=1.5$} & $c_{2}$ & -858.000 & +9512.00 $\alpha_{0}$ & & $-39580.00 \alpha_{0}^{2}$ \\
\hline & $c_{3}$ & 9219.000 & $-105260.00 \alpha_{0}$ & & $+411440.00 \alpha_{0}^{2}$ \\
\hline & $c_{4}$ & -35145.000 & $+417050.00 \alpha_{0}$ & $0-1$ & $550300.00 \alpha_{0}{ }^{2}$ \\
\hline & $c_{0}$ & 0.896 & $+7.24 \alpha_{0}$ & & $-26.5 \alpha_{0}^{2}$ \\
\hline Rod & $c_{1}$ & 21.800 & $-590.40 \alpha_{0}$ & & $+2087.0 \alpha_{0}^{2}$ \\
\hline \multirow[t]{3}{*}{$W / B=2.0$} & $c_{2}$ & -1192.000 & $0+17166.00 \alpha_{0}$ & & $-58980.0 \alpha_{0}{ }^{2}$ \\
\hline & $c_{3}$ & 16772.000 & $-213330.00 \alpha_{0}$ & $x_{0}$ & $+713640.0 \alpha_{0}^{2}$ \\
\hline & $c_{4}$ & -78837.000 & $0+961870.00 \alpha_{0}$ & $x_{0}-3$ & $146400.0 \alpha_{0}^{2}$ \\
\hline
\end{tabular}

Range: $0.18 \leq \alpha_{0} \leq 0.22, \alpha_{0} \leq \alpha \leq 0.8$ 
Table 4--Coefficients for Eq 7

Specimen Coeff. Expression

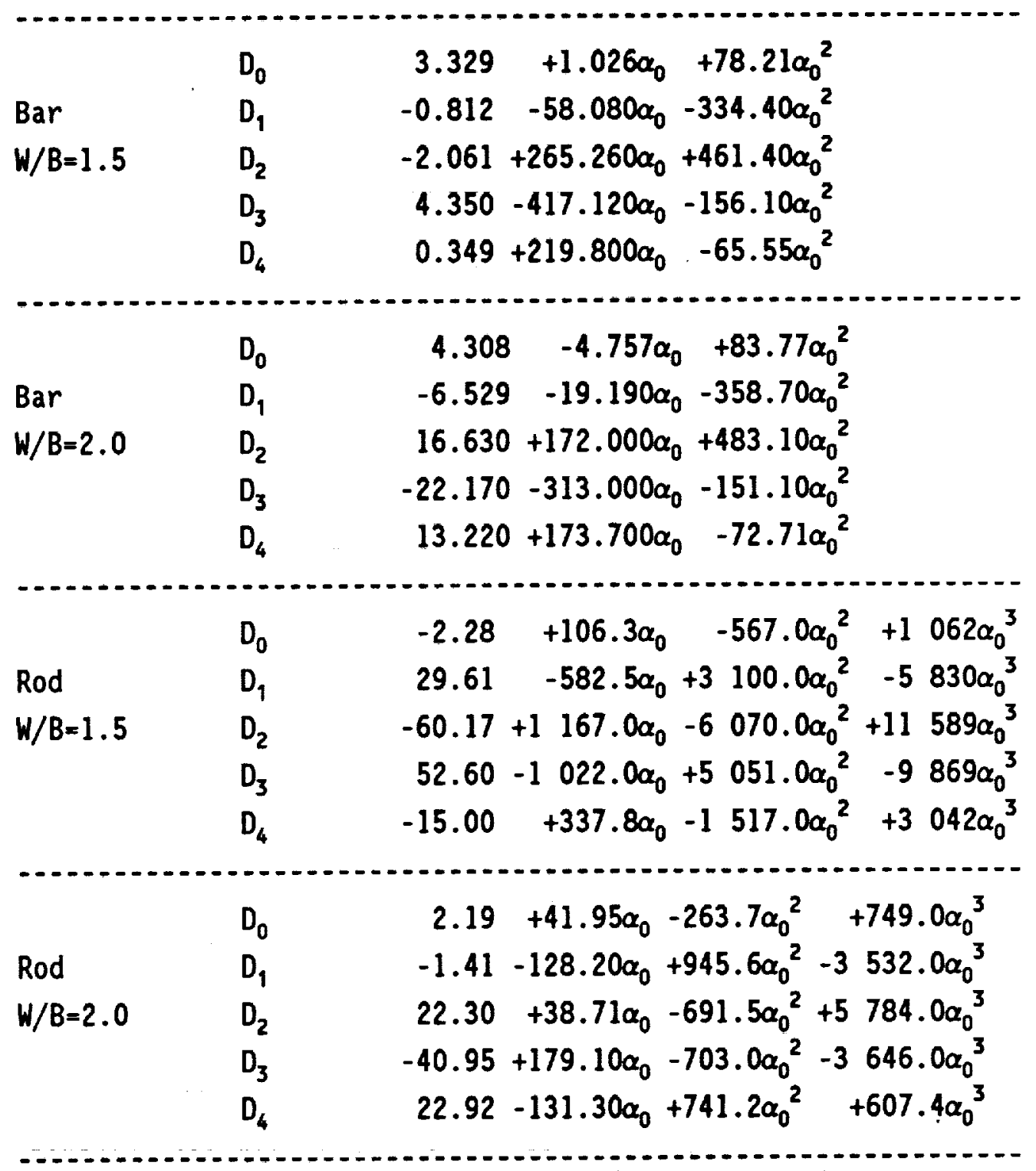

Range: $0.1 \leq \alpha_{0} \leq 0.35$ (bar), $0.1 \leq \alpha_{0} \leq 0.40$ (rod), $\alpha_{0} \leq \alpha \leq 0.8$ 
Table 5--Coefficients for Eq 8 Specimen Coeff. Expression

\begin{tabular}{|c|c|c|c|c|c|}
\hline & $E_{0}$ & 2.850 & $-6.48 \alpha_{0}$ & $+61.56 a_{0}^{2}$ & \\
\hline Bar & $E_{q}$ & 1.177 & $+26.59 \alpha_{0}$ & $-349.30 \alpha_{0}^{2}$ & \\
\hline \multirow[t]{3}{*}{$W / B=1.5$} & $E_{2}$ & 9.650 & $-8.37 \alpha_{0}$ & $+708.90 \alpha_{0}^{2}$ & \\
\hline & $E_{3}$ & -16.240 & $-62.60 \alpha_{0}$ & $-597.00 \alpha_{0}^{2}$ & \\
\hline & $E_{4}$ & 10.450 & $+56.82 \alpha_{0}$ & $+167.90 \alpha_{0}^{2}$ & \\
\hline & $E_{0}$ & 3.885 & $5-17.75 \alpha_{0}$ & $+94.97 \alpha_{0}^{2}$ & \\
\hline Bar & $E_{1}$ & -5.160 & $+123.20 \alpha_{c}$ & $0 \quad-624.20 \alpha_{0}^{2}$ & \\
\hline \multirow[t]{3}{*}{$W / B=2.0$} & $E_{2}$ & 34.270 & $-324.50 \alpha_{c}$ & $0+1562.00 \alpha_{0}^{2}$ & \\
\hline & $E_{3}$ & -52.330 & $+386.80 \alpha_{c}$ & $0-1756.00 \alpha_{0}^{2}$ & \\
\hline & $E_{4}$ & 27.950 & $-173.20 \alpha_{c}$ & $0+741.40 \alpha_{0}^{2}$ & \\
\hline \multirow{5}{*}{$\begin{array}{l}\text { Rod } \\
W / B=1.5\end{array}$} & $E_{0}$ & 3.91 & $-23.18 \alpha_{0}$ & $+138.4 \alpha_{0}^{2}$ & $-91.84 \alpha_{0}^{3}$ \\
\hline & $E_{1}$ & -10.01 & $+237.70 \alpha_{0}$ & $-1356.0 \alpha_{0}^{2}+1$ & $1325.00 \alpha_{0}^{3}$ \\
\hline & $E_{2}$ & 51.60 & $-758.80 \alpha_{0}$ & $+4284.0 \alpha_{0}^{2}-4$ & $4777.00 \alpha_{0}^{3}$ \\
\hline & $E_{3}$ & -74.66 & $+969.60 \alpha_{0}$ & $-5480.0 \alpha_{0}^{2}+6$ & $6516.60 \alpha_{0}^{3}$ \\
\hline & $E_{4}$ & 37.83 & $-433.00 \alpha_{0}$ & $+2464.5 \alpha_{0}^{2}-3$ & $3043.00 \alpha_{a}^{3}$ \\
\hline \multirow[b]{2}{*}{ Rod } & $E_{0}$ & 2.92 & $+0.28 \alpha_{0}$ & $+26.67 \alpha_{0}^{2}$ & $+33.27 \alpha_{0}^{3}$ \\
\hline & $E_{1}$ & 1.68 & $+28.52 \alpha_{0}$ & $-336.00 \alpha_{0}^{2}$ & $+111.40 \alpha_{0}{ }^{3}$ \\
\hline \multirow[t]{3}{*}{$W / B=2.0$} & $E_{2}$ & 20.59 & $-135.84 \alpha_{0}$ & $+1157.00 \alpha_{0}^{2}$ & $-918.40 \alpha_{0}{ }^{3}$ \\
\hline & $E_{3}$ & -39.16 & $+218.10 \alpha_{0}$ & $-1581.00 \alpha_{0}^{2}+$ & $+1581.00 \alpha_{0}^{3}$ \\
\hline & $E_{4}$ & 22.64 & $-115.78 \alpha_{0}$ & $+756.60 \alpha_{0}^{2}$ & $-837.20 \alpha_{0}{ }^{3}$ \\
\hline
\end{tabular}




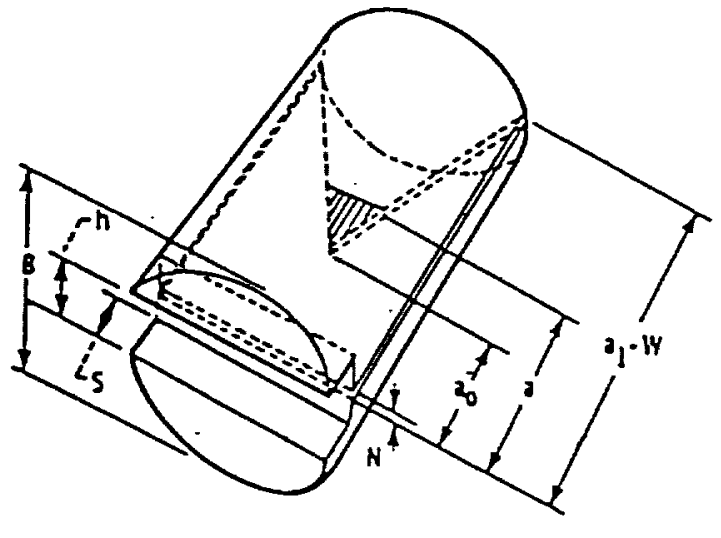

(a) rod

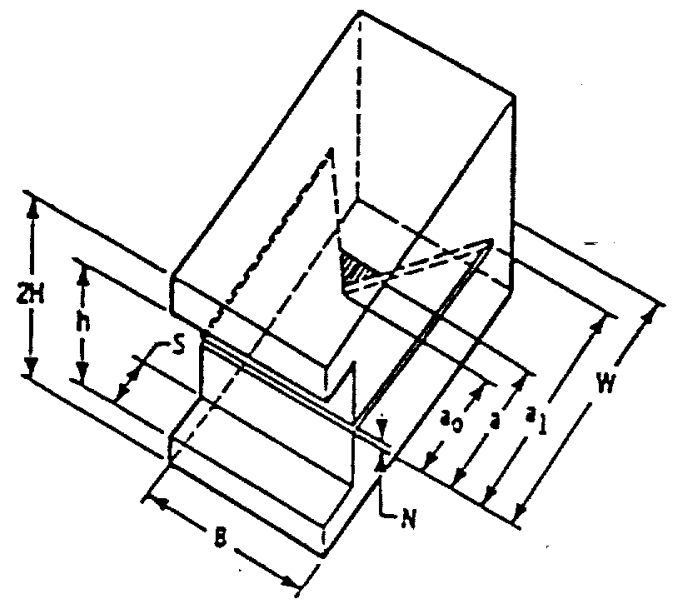

(b) bar

FIG. 1 - Chevron-noteh rod and bar specimens.

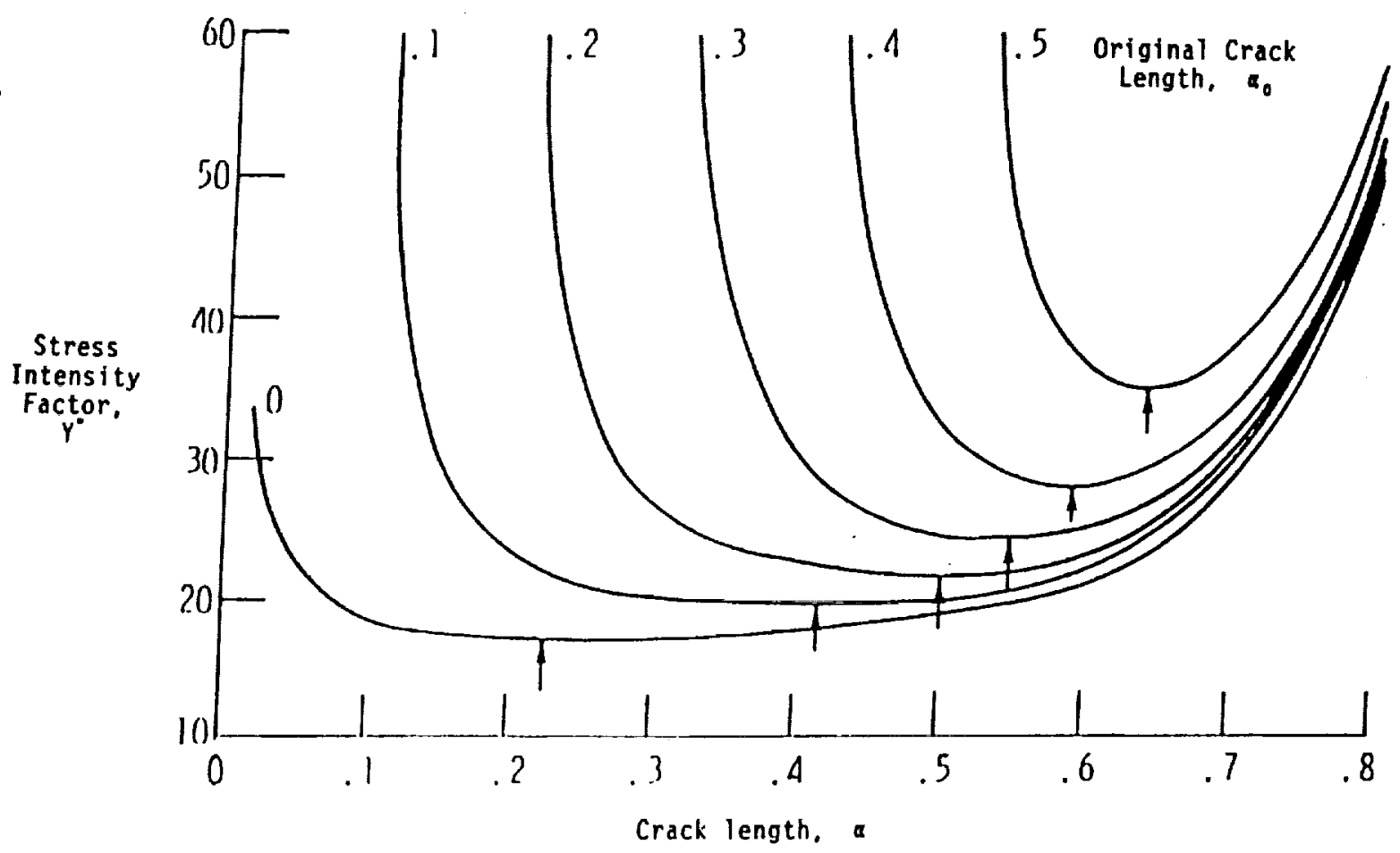

FIG. 2 - Typical variation of stress intensity factor with crack length for chevron-notch specimens [1]. Arrows denote minima. 


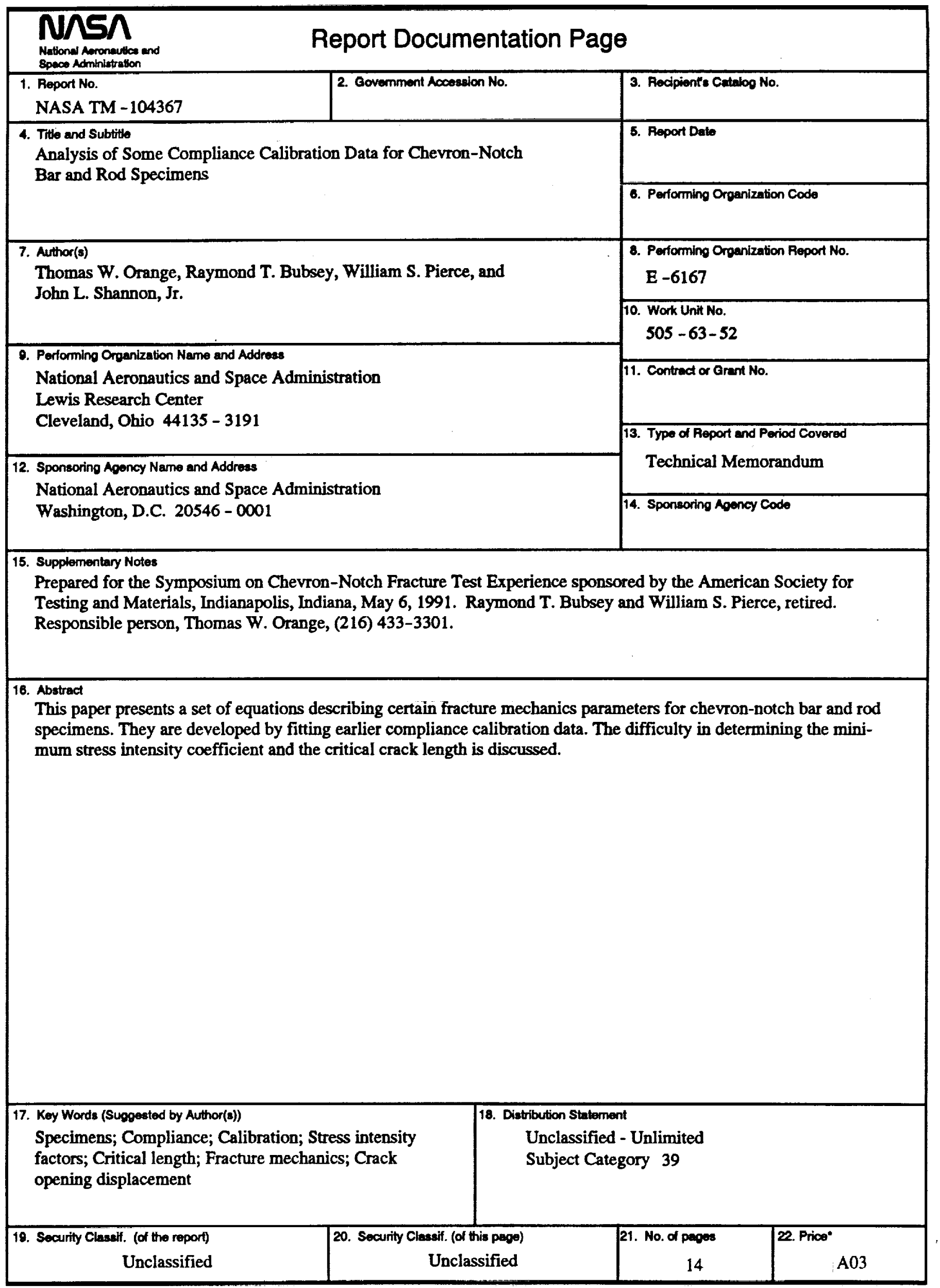

